\title{
Study of normal ECGs of healthy Nepalese Medical personals without any apparent Medical illness.
}

\author{
Manoj Nepal*, AB Upadhayaya**, L Tibrewal ${ }^{* * *}$, PR Regmi***, K \\ Acharya $^{* * *}$, AK Shah ${ }^{\star * *}$, HH Khanal ${ }^{* \star *}$, S Shrestha ${ }^{* *}$, S Rajbhandari***
}

\begin{abstract}
:
Objective:

To find the normal electrocardiographic duration, intervals, and axis in a healthy group of Nepalese doctors, nurses and medical representatives and to see if these figures differ from the standard values described in the textbooks and literature.
\end{abstract}

\section{Setting:}

Cardiology unit of Bir hospital, a national postgraduate referral hospital and part of National Academy Of Medical Sciences.

\section{Methodology:}

All the participants were told and consented for the study Total of 101 participants took part in the study including 65 male and 36 female participants. ECG was taken at cardiology outpatient department (OPD) of Bir hospital for a week with help of a trained ECG technician by using portable Cardimax ECG machine. Electrocardiographic duration, intervals and axis were measured and compared with the standard value.

\section{Results:}

All electrocardiographic duration and intervals derived from the present study including $p$ wave, QRS, Tand PQ, QT and QTc were within normal limits as is described in the literature with minor variations.

\section{Conclusion:}

Though all ECG parameters were within normal limits minor EGG variations should be taken into account while interpreting electrocardiograms in Nepalese population.

Key words: normal ECG, healthy Nepalese Medical Personnel, and Kathmandu, Nepal 


\section{Introduction:}

Electrocardiogram also known as ECG or EKG (from German word) is a recording of the electrical activity of the heart (1) by placing specific electrodes at different specific locations of the body. This is one of the oldest cardiac investigative tools still practiced successfully throughout the world. Even after so many years of its use many significance is still becoming apparent. People of different ethnic backgrounds and people of different age and sex have got different lifestyle and socioeconomic standards that might influence the electrocardiographic measurements (2). Some normal ECG changes specifically seen in females may not seen in males and similarly some nonspecific changes might be seen in apparently normal individuals. There was one similar study (2) done in Nepalese doctors but it included few doctors only in its study so we decided to conduct a broader study including male and female of different ages to see normal individual variability of ECG parameters and its mean in the studied population and the value was compared with standard value described in the literature.

\section{Methodology:}

All the participants were told verbally and consented tor the study. Total of 101 participants took part in the study including 65 male and 36 female participants. Medical doctors, sisters, staff nurses and medical representative between the ages of 17 and 40 years were included in the study. Those not having medical illness especially cardiac disease and not taking any medicine including those of B blockers, anxiolytic and antihistamines were included. Before taking ECG history about medical illness was taken and they were told to take at least 15 minutes of rest. ECG was taken at cardiology outpatient department (OPD) of Bir hospital for a week with help of a trained ECG technician by using portable Cardimax ECG machine. 12 lead ECG at the speed of $25 \mathrm{~mm} / \mathrm{sec}$ were recorded with proper standardization and amplitude of $25 \mathrm{~mm} /$ millivolt and a minimum of four ECG complexes were recorded with long rhythm strips. Electrocardiographic duration, intervals and axis were measured (3) with the help of ruler; caliper, protracter and mean value of at least four complexes were taken which was verified by independent cardiologists and compared with the standard value.

* Correspondence: Dr Manoj Nepal ph No 332520, GPO Box No 19798,

Kathmandu, Nepal, Email-manojnepal@yahoo.com

* PG resident in cardiology

${ }^{* *} H O D$ of medicine and cardiolegy unit chief Bir Hospital

** Cardiology unit Bir hospital 
- NEPALESE HEART JOURNAL •

(Bar diagram showing male and female)
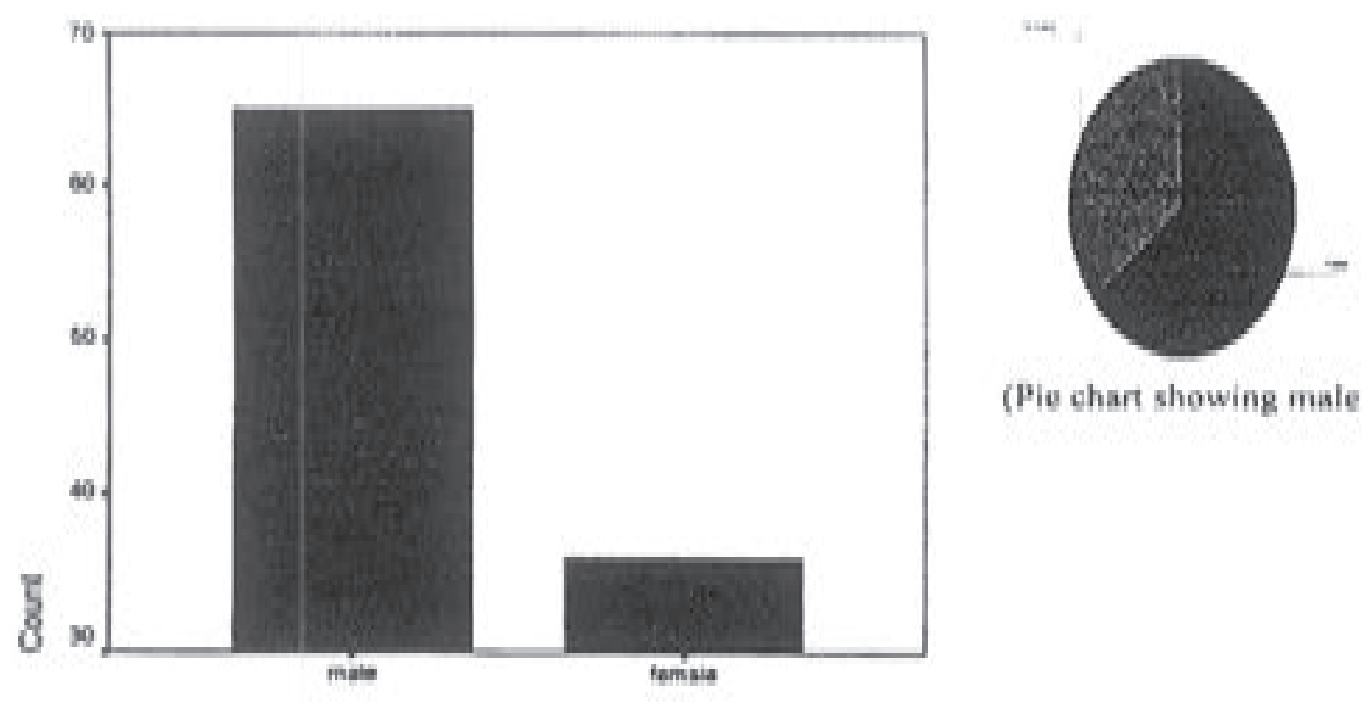

(Po shan showing male and fomale)

Wha

Pic chart showing different study populations)

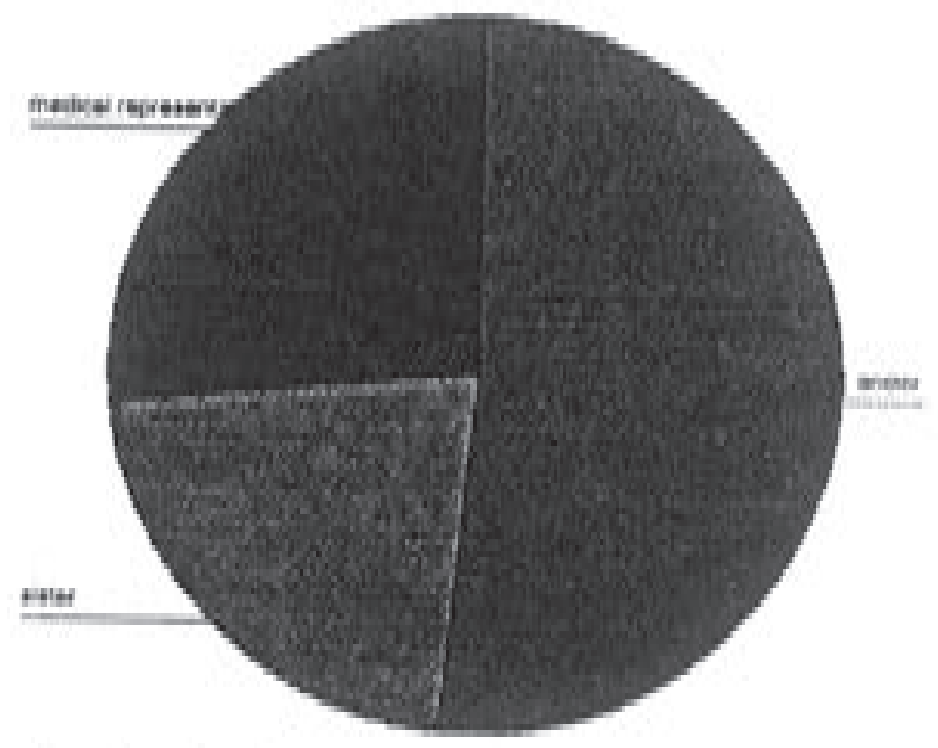

Plo chart showing difforont study populations) 
- NEPALESE HEART JOURNAL •

\section{Result:}

The final result of the study is tabulated below.

\begin{tabular}{|l|l|l|l|l|l|l|l|l|l|}
\hline & \multicolumn{2}{|l|}{ Male(N=65) } & \multicolumn{3}{l|}{ Female(N=36) } & \multicolumn{2}{l|}{ Combined (N=101) } \\
\cline { 2 - 11 } & Max & Min & Mean & Max & Min & Mean & Max & Min & Mean \\
\hline Age (years) & 39 & 22 & 28.46 & 32 & 17 & 23.62 & 39 & 17 & $26.04 \pm 4.81$ \\
\hline $\begin{array}{l}\text { R-R Interval (Milli } \\
\text { sec) }\end{array}$ & 1133 & 497 & 817 & 1086 & 528 & 762 & 1109.5 & 512.5 & $\begin{array}{l}789.5 \pm \\
14.51\end{array}$ \\
\hline $\begin{array}{l}\text { Heart rate } \\
\text { (Milli sec) }\end{array}$ & 121 & 53 & 73 & 114 & 55 & 79 & 121 & 53 & $\begin{array}{l}76.29 \pm \\
12.04\end{array}$ \\
\hline $\begin{array}{l}\text { P wave } \\
\text { (Milli sec) }\end{array}$ & 110 & 52 & 83 & 105 & 60 & 81 & 110 & 52 & $\begin{array}{l}81.31 \pm \\
10.93\end{array}$ \\
\hline $\begin{array}{l}\text { PQ Interval } \\
\text { (Milli sec) }\end{array}$ & 180 & 100 & 144 & 176 & 85 & 139 & 180 & 85 & $\begin{array}{l}142.06 \pm \\
19.41\end{array}$ \\
\hline $\begin{array}{l}\text { QRS duration } \\
\text { (Milli sec) }\end{array}$ & 90 & 40 & 63.81 & 80 & 40 & 60.62 & 90 & 40 & $\begin{array}{l}62.01 \pm \\
13.15\end{array}$ \\
\hline $\begin{array}{l}\text { T wave } \\
\text { (Milli sec) }\end{array}$ & 188 & 95 & 144.07 & 173 & 110 & 136.58 & 188 & 95 & $\begin{array}{l}142.79 \pm \\
17.44\end{array}$ \\
\hline $\begin{array}{l}\text { QT Interval } \\
\text { (Milli sec) }\end{array}$ & 405 & 280 & 329.37 & 400 & 288 & 336.63 & 405 & 280 & $\begin{array}{l}331.96 \pm \\
27.12\end{array}$ \\
\hline $\begin{array}{l}\text { QTc Interval } \\
\text { (Milli sec) }\end{array}$ & 439 & 299 & 366.13 & 459 & 355 & 386.72 & 459 & 299 & $\begin{array}{l}374.36 \pm \\
26.03\end{array}$ \\
\hline P wave axis & 90 & 0 & 51.92 & 60 & 0 & 46.52 & 90 & 0 & $49.11 \pm 19.36$ \\
\hline QRS axis & 90 & -15 & 52.82 & 90 & 15 & 56 & 90 & -15 & $54.07 \pm 21.99$ \\
\hline T wave axis & 90 & 0 & 39.46 & 60 & 0 & 43.19 & 90 & 0 & $40.84 \pm 21.24$ \\
\hline
\end{tabular}




\section{- NEPALESE HEART JOURNAL •}

Out of 101 patients studied males were 65 and females numbered 36 with a mean age range of 28.46 and 23.62 years respectively. The maximum age of male subject was 39 years and minimum was 22 while that of female was 32 and 17 years. Maximum RR interval of 1133 and minimum of 817 Milli sec was observed in males with max heart rate of 121 and minimum of 53 while it was 1086 milli sec and 528 Milli sec yielding heart rate of 114 as max and 55 as minimum in females. Values of $P$ wave observed were 110 Milli sec as max and 52 Milli sec as minimum in males while the figures were 105 and 60 Milli sec in females, Mean PQ interval was 144 Milli sec in males with maximum value of 180 Milli sec and minimum value of 100 Milli sec while the similar values were 176 and 85 Milli sec with mean value of 139 Milli sec in females. QRS duration ranged from 40-to1090 Milli sec with mean value of 63.81 Milli sec in males and 40 to 80 Milli sec with mean value of 60.62 Milli sec in females. T wave ranged from 95 to 188 Milli sec with mean value of 144.07 Milli sec in males while the similar values were 110 and 173 Milli sec with mean value of 136.58 Milli sec in females. Males had maximum QT interval of 405 Milli sec and minimum of 280 Milli sec with mean value of 329.37 and the corresponding values in females were 400 and 288 Milli sec with mean value of 386.72 Milli sec. Corrected QT (QTc) ranged from 299 to 439 Milli sec in males with mean value of 366.13 and the same value in females were 355 to 459 Milli sec with mean value of 386.72 Milli sec. Similarly P, ORS and T wave axes spread from 90 to $0,-15$ and 0 degree respectively with the corresponding mean value of $51.92^{\circ} \% 52.82^{\circ}$, and $39.46^{\circ}$ while in females they were 60,90 , and 60 degrees to 0,15 and 0 degrees with mean values of $46.52,56$ and 43.19 degrees.

According to the literature normal $P$ wave duration is $60-100$ Milli sec and normal amplitude is less than 2.5 millimeter. In our study mean $P$ wave was 83 and 81 Milli sec in males and females respectively, but the maximum and minimum value exceeded in males and max value In females so the difference was not significant. $(1,2,3)$

The normal PQ interval is $120-220$ Milli sec in literature, which in our study was 144 and 139 Milli sec in males and females respectively with max and minimum value of 180-100 milli sec in males and 176-85 Milli sec in females respectively, thus being well within the normal range. $(1,2,3)$

Normal duration of QRS complex is usually 50-100 Milli sec, which in our study was 63.81 and 60.62 in males and females respectively with max to min range being 90-40 and $80-40$ respectively. $(12,3)$

T waves are usually not more than 5 millimeter in any standard leads and 10 millimeter 
in any precordial leads which in our study were 144.07 and 136.58 milli sec in males and females respectively.

The normal range of QTC is from 350-430 milli see, which in our study was 366.13 and 386.72 milli sec in males and females.(1)

The normal mean manifest frontal plane $P$ wave axis is directed within 40 to 60 degrees which in our study were 51.92 and 46.52 degrees in males and females respectively. Similarly QRS and T wave axes along with QRS-T angle were not significantly different from the described value in the literature.

The findings of the study are being compared in table (2) with similar studies Findings done by Dr DB Karki and Dr Sudhir lohani in table 3,4,and 5, (2)

Tablo (2)

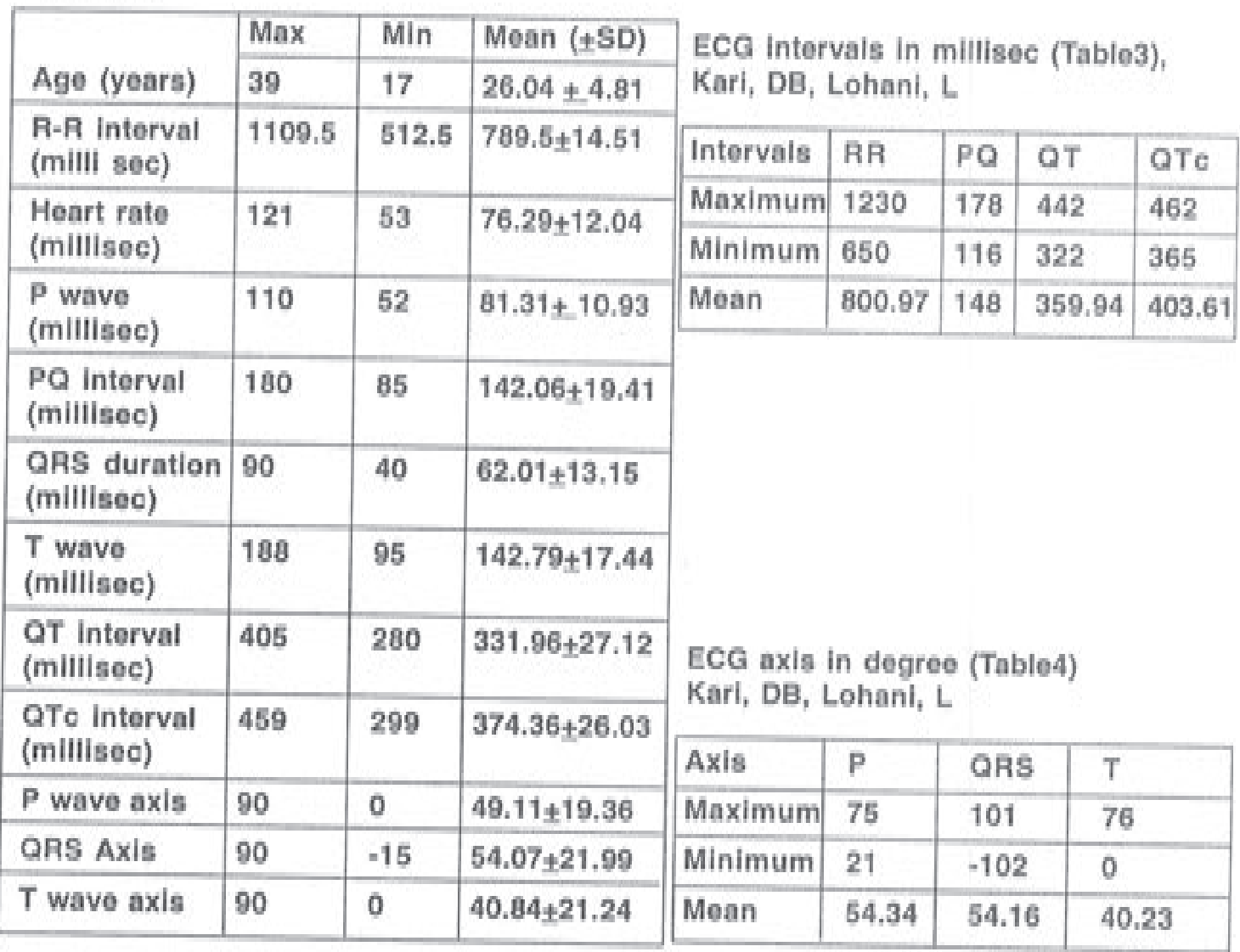

(ECa duration in milisoc) (Tablo 5) DB Karki, 5 Lohan!

\begin{tabular}{|l|l|l|l|l|}
\hline Duration & P & QRS & T & HA \\
\hline Maximum & 122 & 104 & 348 & 92 \\
\hline Minimum & 90 & 74 & 248 & 50 \\
\hline Moan & 104.69 & 87.68246 .39 & 76.42 \\
\hline
\end{tabular}


This comparison shows that $P$ wave duration was well within the normal values in our study as compared to that of the previous study. RR interval, heart rate, and PQ were not significantly different. QRS duration, QT and QTc though different were not statistically significant from those described in the literature, P, QRS and T wave axes were similar and the difference is insignificant.

\section{Statistical analysis:}

Maximum, minimum, mean values and standard Deviation was calculated and their significance checked with the standard values described in the literature and with that of the previous study done in Nepal. Statistical analysis package program SPSS8.0 was utilized for analysis.

\section{Discussion\& Conclusion:}

Einthoven, using an improved electro-meter and a correction formula developed Independently of Burch, distinguished five deflections, which he named $P Q, A$, Sand $T$,

The four deflections prior to the correction formula were labelled ABCD and the 5 derived deflections were labelled PQRST. The choice of $\mathrm{P}$ was a mathematical convention by using letters from the second half of the alphabet. $\mathrm{N}$ had other meanings in mathematics and $\mathrm{O}$ was used for the origin of the Cartesian coordinates. In fact einthoven used $\mathrm{O} \ldots . . \mathrm{X}$ to mark the timeline on his diagrams. $P$ is simply the next letter.

Einthoven invented a new galvanometer for producing electrocardiograms using a fine quartz string coated in silver based on ideas by Deprez and d' personal (who used a wire coil). His "string galvanometer" weighed 600 pounds. $(6,7)$

In 1902 Einthoven published the first electrocardiogram recorded on a string galvanometer. In 1903 Aventine discussed commercial production of a string galvanometer with Max Mandela of Munich and Horace Darwin of Cambridge Scientific Instruments Company of London. Cambridge scientific company produced the first commercial machine in 1911 in England. Later many advancements and modification were done before we finally have very light and Portable machines,

In 1942 Emanuel Goldberger increased the voltage of Wilson's unipolar leads by 50\% and created the augmented limb leads aVR, aVL and aVF. When added To einthoven's three limb leads and the six chest leads we arrive at the 12-lead electrocardiogram that is used today. 
Later Arthur Master could utilize it for exercise test for cardiac function int 1942. (8)

Later different significant findings were discovered using ECG as an investigative tool in cardiology that is still being used today. There are interesting findings and correlation of ECG findings with different conditions. (9, 10,11) Even so different lifestyles and body habitus can have some different ECG findings for which this study was done.

This study highlighted that all the ECG parameters in the Nepalese population were with in normal range including that of $P$ wave and QRS duration, which after Karki and lohani's study were thought to be on the higher side. However some individual values exceeded from that described in the literature so such values should be understood while evaluating electrocardiograms of Nepalese population.

\section{Acknowledgment:}

We would like to thank to all those doctors, nurses and medical representatives who voluntarily participated in the study, Our special thanks to Dr Sanjay Shrestha for statistical analysis and Mrs. Ansuka Rajopadhayaya and Anita Shrestha for taking all those ECGs.

\section{References:}

1. Schamroth L. An Introduction to Electrocardiography.7" Ed, special IE reprint for India 1997. Blackwell Scientific Publications, Oxford: 1990.

2. Karki DB, Lohani S. Electrocardiographic Intervals, Durations, and Axis of Healthy Nepalese doctors with normal électrocardiogram, JNMA: 1998: 37:413-421.

3. Galen S. Wagner. Marriott's practical electrocardiography. Tenth Ed, Lipping Williams \& Wilkins, USA, 2001.

4. Eugene Braunwald et al "Harrison's Principles of Internal Medicine "Me Grew Hill \& Company 15" Ed, 2001,

5. Wehr M et al. Cardiac findings in alcoholic liver disease; med kiln, 1990 Nov 15; 85 (11): 629-36,681.

6. Fye WB. A history of the origin, evolution, and impact of electrocardiography. Am J Cardiol 1994; 73:937-949 (Goggle search) 
7. Einthoven W. Umber die Form des mensch lichen Electrocardiograms. Arch fd Ges Physiology 1895; 60:101-123. (Medline search)

8. Master AM, Friedman R, Dack S. The electrocardiogram after standard Exercise as a functional test of the heart. Am Heart J. 1942: 24:777 (Melinde Search)

9. Brugada P, Brugada J. Right Bundle Branch Block, Persistent ST Segment Elevation and Sudden Cardiac Death: A Distinct Clinical and Electrocardiographic Syndrome. J Arn Coll Cardiol 1992; 20:1391-6

10. Jervell A, Langa-Nielsen F, Congenital deaf mutism, functional heart disease with prolongation of the QT interval and sudden death. Am Heart J 1957; 54:59.

11. Ward OC, New familial cardiac syndrome in children, J Irish Med Assoc. 1964; 54:103-6 